\title{
Strategies to Utilise Advanced Heat Shield Technology for High-Payload Mars Atmospheric Entry Missions
}

\author{
Max Braun, Paul Bruce, Errikos Levis ${ }^{1}$ \\ Departement of Aeronautics, Imperial College London, London, SW7 $2 A Z$
}

\begin{abstract}
Present Entry, Descent and Landing (EDL) technology for interplanetary missions does not have the capabilities to meet the demanding requirements that come with future missions. A popular target for such missions is Mars and today efforts are made to send manned as well as sophisticated robotic probes to the Martian surface. Because present EDL technology has reached its limits, fundamentally new approaches are needed to significantly extend capabilities. Systematic evaluation of novel EDL technologies and optimization of EDL strategies are crucial needs for conceptual design. A computational framework will be presented tailored to enable systematic EDL analysis with special regards to novel EDL technology and event strategies. The benefits of flexible heat shield concepts that come with liberties in the choice of the ballistic coefficient will be shown in comparison with solid shield alternatives for payload classes of 2, 25 and 40 tonnes to show potential for manned and robotic missions. Furthermore, benefits of the new methodology for novel EDL event strategies are presented and discussed. The introduced methodology will help designers exploit new directions for conceptual design regarding EDL systems in terms of entry mass optimization and mission capabilities.

Keywords: Mars, EDL, Supersonic-Retropopulsion, Re-entry, Flexible Heat shields
\end{abstract}

Preprint submitted to Journal of ${ }^{A} T_{E} X$ Templates

January 12, 2017 


\section{Nomenclature}

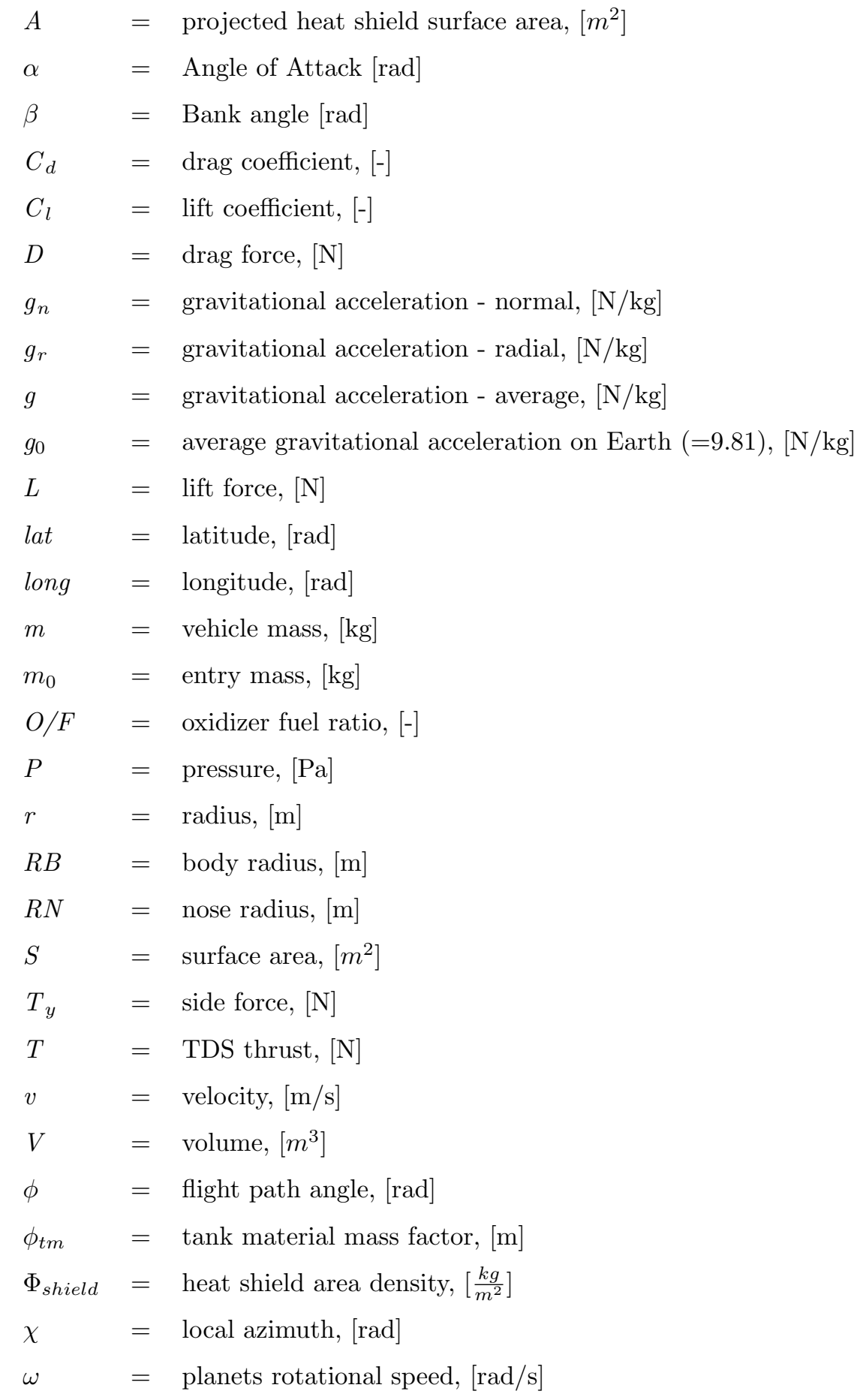




$\begin{array}{ll}\text { Abbreviations } \\ \text { AoA } & \text { Angle of Attack } \\ B C & \text { Ballistic Coefficient, }\left[\frac{\mathrm{kg}}{\mathrm{m}^{2}}\right] \\ D G B & \text { Disk-Gap-Band (Parachute) } \\ E D L & \text { Entry, Descent and Landing } \\ F P A & \text { Flight Path Angle } \\ I S P & \text { Specific Impulse, [s] } \\ M M H & \text { Monomethylhydrazine } \\ M O L A & \text { Mars Orbiter Laser Altimeter } \\ N T O & \text { Dinitrogen Tetroxide } \\ \text { ODE } & \text { Ordinary Differential Equation } \\ R C S & \text { Reaction Control System } \\ S R P & \text { Supersonic Retro-propulsion } \\ T D S & \text { Terminal Descent System } \\ T P S & \text { Thermal Protection System }\end{array}$

\section{Introduction}

Today Mars is a popular target for prospective planetary missions, robotic as well as human. Since the first lander tried to reach the Martian deserts in 1971 almost half of all landing missions to the red planet have failed, which highlights the challenging nature of this target. Faced with these appreciable challenges engineers and scientists focused significant effort and resources on development of sophisticated and reliable space vehicles for fulfilling many challenges of such missions. Nevertheless, even the most recent missions are based on technology developed during the Viking program in the 1960's. Present Mars missions Entry, Descent and Landing (EDL) capabilities are reaching their limits [1] and for future extra-terrestrial exploration missions, it is essential that we overcome the limitations of today's technology.

A particular problem facing Mars entry vehicles is the thin atmosphere and relatively high gravity, which restricts the maximum ballistic coefficient reachable 
for classic rigid blunt body heat shield designs [2]. The ballistic coefficient (BC) is a characteristic variable to describe atmospheric entry devices and is defined as follows:

$$
B C=\frac{m_{0}}{C_{d} A}
$$

Where $\mathrm{m}_{0}$ is the entry mass, A the surface area and $\mathrm{C}_{d}$ the average drag coefficient. For a classic blunt body design the key issue is that for a given maximum ballistic coefficient the capsule diameter increases proportional to $\sqrt{m_{0}}$. A maximum BC for Mars entry capsules of $150 \frac{\mathrm{kg}}{\mathrm{m}^{2}}$ has often been quoted [1] and relies on a classic three event EDL maneuver using a supersonic parachute. The use of alternative final event technology is likely to allow higher BC, but a limit on BC remains for every rigid EDL design facing thin atmospheres. Note 30 that although the drag coefficient influences the diameter in this calculation, it has been shown that the drag coefficient is largely insensitive to lift-to-drag ratio or heat shield shape changes and can be approximated as a constant in the range of $1.4<C_{d}<1.6$ over a wide range of hypersonic Mach numbers [3]. Note that this assumption is only valid for blunt body capsule shapes. Figure 351 shows the relation between heat shield diameter and mass for classic capsule technology with different BC. Also outlined is the zone reached by past Mars missions (green box) and the zone engineers have to reach to enable human Mars missions (blue box), based on recent studies [4]. One can see the significant gap between present capabilities and future demands. Also it becomes obvious that

40 blunt body concepts for high payload atmospheric entry have to provide large frontal areas to meet given ballistic coefficient constraints.

To bridge this gap various alternative EDL designs have been proposed and examined [5]. One of the most promising options today is the class of extendable heat shields. Figure 2 shows a deployable heat shield concept in its stowed and 45 deployed configurations, alongside a photograph showing the layer structure of a flexible heat shield fabric. To comply with given maximum launcher fairing diameter limits these shields are made of a flexible material. Unfolded to full 


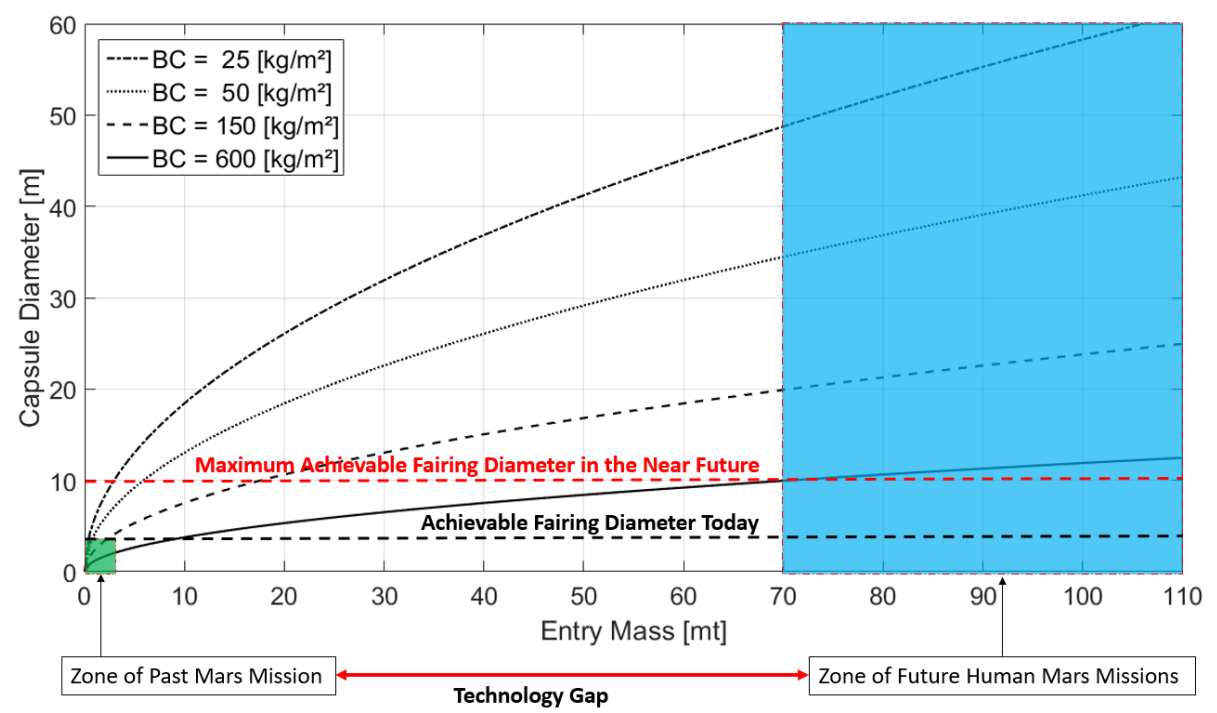

Figure 1: Technology gap and relation between ballistic coefficient and capsule diameter

size in space they can reach the massive diameters needed for high payload EDL missions (see figure 1). Present launchers can accommodate capsule diameters up to 4.57 meters (Ariane $5[6$ and Atlas V-500 [7]). For the near future there are larger launch structures in development. For example, the SLS Block II will be able to accommodate diameters up to 10 meters 8 .

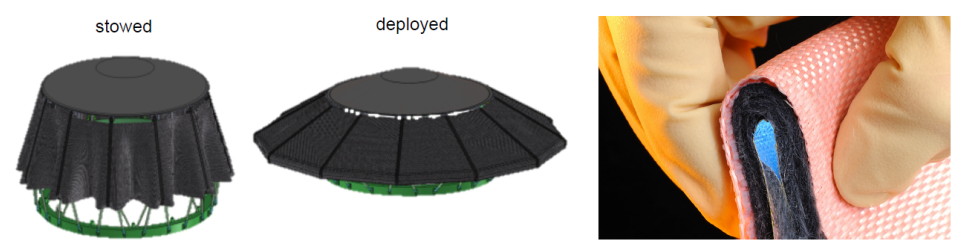

Figure 2: Flexible Heat shield designs: ADEPT concept (left) 9$]$ and flexible thermal protection system (TPS) (right) 10

Today, many methods exist to design and optimize classic EDL sequences, invariably consisting of rigid heat shield, supersonic parachute and a retropropulsion terminal descent event. All Mars missions to date have adopted this approach, with only minor changes in the final events choice [1, 11. As such engineers are less experienced when it comes to compiling and optimizing 
EDL sequences tailored to the demands of high payload missions. In order to capitalise on recent advances in technology, new methods are required to systematically compare given alternatives in a precise manner and identify optimal solutions.

To this end, a methodology to effectively compare different flexible heat shield technologies in combination with various EDL event sequences is presented in this paper. The primary aim is to relate a given payload mass directly to resulting entry masses, independently from details of the heat shield technology. Accordingly, low resulting entry masses correspond to high mass efficiencies of candidate designs. Furthermore the methodology can be used to find optimized configurations in event sequence composition and vehicle design.

This article proceeds with a short overview over the utilised modeling and com70 putational methods, followed by a discussion on potential EDL technology and event design options. Afterwards the methodology to evaluate EDL technology will be presented. Applied to two candidate mission designs, the value of this approach will be shown. Finally the results will be discussed, concluded by recommendations for EDL architectures for future Mars missions.

\section{2. Computational framework}

A three degree of freedom model has been used to compute the trajectories for the following analysis. The code is written in $\mathrm{C}++$ and uses the "odeint" library to solve ordinary differential equations (ode's). To compute the trajectory, equations for position and velocity vectors have to be solved. Time derivations of the position vector are defined as follows:

$$
\begin{aligned}
\text { long } & =v \cos (\phi) \frac{\sin (\chi)}{r \cos (\text { lat })} \\
\text { lat } & =v \cos (\phi) \frac{\cos (\chi)}{r} \\
\dot{\mathbf{r}} & =v \sin (\phi)
\end{aligned}
$$


Time derivations of the velocity vector can be written following the method of [12]:

$$
\begin{aligned}
\dot{\mathbf{v}} & =-g_{r} \sin (\phi)+g_{n} \cos (\chi) \cos (\phi)+\frac{D}{m}+\omega^{2} r \cos (\text { lat }) \\
& {[\sin (\phi) \cos (\text { lat })-\cos (\phi) \cos (\chi) \sin (\text { lat })] } \\
\dot{\phi} & =\left[\frac{v}{r}-\frac{g}{r}\right] \cos (\phi)-g_{n} \cos (\chi) \frac{\sin (\phi)}{v}+\frac{L}{v m}+2 \omega \sin (\chi) \cos (\text { lat }) \\
& +\omega^{2} r \cos (\text { lat }) \frac{\cos (\phi) \cos (\text { lat })+\sin (\phi) \cos (\chi) \sin (\text { lat })}{v} \\
\dot{\chi} & =v \sin (\chi) \tan (\text { lat }) \frac{\cos (\phi)}{r}-g_{n} \frac{\sin (\chi)}{v}-\frac{T_{y}}{v-\cos (\phi) m}- \\
& 2 \omega[\tan (\phi) \cos (\chi) \cos (\text { lat })-\sin (\text { lat })]+\omega^{2} r \sin (\chi) \sin (\text { lat }) \frac{\cos (\text { lat })}{v \cos (\phi)}
\end{aligned}
$$

The aerodynamic forces for lift (L) and drag (D) are computed as follows.

$$
D=\frac{1}{2} \rho v^{2}\left[C_{d, \text { total }} S+C_{d, \text { parachute }} S_{\text {parachute }}\right]
$$

The capsules drag coefficient is composed of parts from aerodynamic drag $\left(C_{d}\right)$ and thrust $\left(C_{T}\right)$.

$$
C_{d, t o t a l}=C_{d}+C_{T}
$$

Where $C_{T}$ is the thrust coefficient.

$$
C_{T}=\frac{F_{T}}{\frac{1}{2} \rho v^{2} S}
$$

$F_{T}$ is the effective thrust force. The coefficients $C_{T}$ and $C_{\text {parachute }}$ are used to simulate final event operations. As a result these are non-zero only in the simulated manoeuvre region. For simulations with angle of attack a lift to drag ratio $\left(\frac{L}{D}\right)$ is required as input variable. Hence the lift can be written depending on the drag.

$$
L=\frac{1}{2} \rho v^{2} C_{d} \frac{L}{D} S
$$

A similar approach yields the side force $T_{y}$. For the presented study however side forces are assumed to be negligible. Because the system mass is not constant 
during EDL maneuvers an additional equation has to be solved to take the loss of fuel into account.

$$
\dot{\mathbf{m}}=-T /\left(I S P g_{0}\right)
$$

Next to the loss of fuel the mass loss as a consequence of a heat shield jettison can be taken into account as an instant change. The presented ODEs are solved using stepwise numerical integration. Figure 3 shows an example trajectory, calculated with the presented method. The simulation shows the first two 80 events containing initial entry and supersonic parachute maneuver of the NASA Phoenix Mars landing mission in 2008 in comparison with reference data from a mission reconstruction analysis by NASA [13].

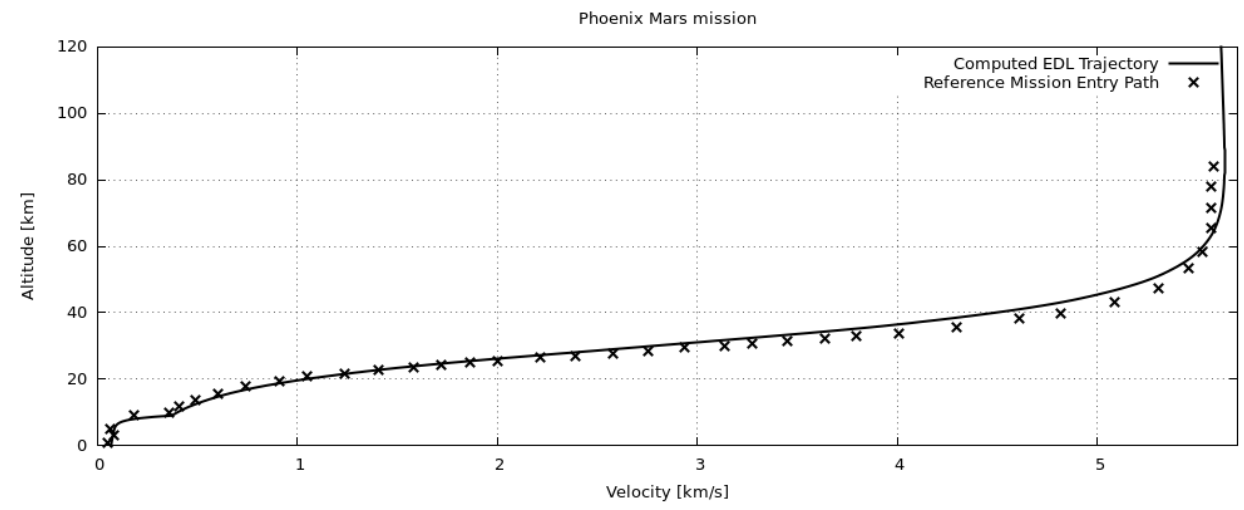

Figure 3: Reconstructed trajectory for the NASA Phoenix Mars landing mission, reference data from 13 .

Several inputs are required to solve equations 2 to 7 To take gravitational forces into account a simplified model that considers the planet's oblateness due to rotational forces, in form of a polynomial geoid model represented by the first constant $J_{2}$, is used [14. Note that within this analysis gravitational forces are secondary due to the fact that within the simulated entry window aerodynamic forces surpass gravitational influences significantly. Nevertheless they are not negligible completely. Another required input are aerodynamic forces. To calculate these, information about aerodynamic behaviour of the simulated 
capsule design is needed, as well as information about atmospheric properties like temperature, pressure, density and gas composition. For conceptual design problems with blunt body vehicles travelling at hypersonic velocities it is common to use Newtonian impact theory to rapidly calculate pressure distributions along arbitrary surfaces, extract aerodynamic data and derive aerodynamic coefficients. For this analysis a three dimensional Newtonian impact theory code (NewAero3D) has been written in Matlab and is used to calculate lift and drag coefficients in hypersonic conditions. The code relies on the modified Newtonian impact theory using the following equation:

$$
C_{p}=C_{p, \max } \sin ^{2}(\theta)
$$

Where $C_{p}$ is the pressure coefficient and $\theta$ the local impact angle. The maximum pressure coefficient at stagnation point $C_{p, \max }$ can be obtained by the following equation:

$$
C_{p, \max }=\frac{2}{M_{\infty}^{2} \gamma}\left(\left[\frac{(\gamma+1)^{2} M_{\infty}^{2}}{4 \gamma M_{\infty}^{2}-2(\gamma-1)}\right]^{\frac{\gamma}{\gamma-1}}\left[\frac{1-\gamma+2 \gamma M_{\infty}^{2}}{\gamma+1}\right]-1\right)
$$

$M_{\infty}$ is the free stream Mach number and $\gamma$ the free stream isentropic exponent. Figure 4 shows results for the pressure coefficient created with this code for different heat shield shapes.

To determine atmospheric properties along trajectories, the ESA Mars Climate Database 5.2 is used [15]. Figure 5 shows results for pressure distribution across the heat shield area for the Orion lens computed with the presented code (NewAero3D) in comparison with the widely used industrial tool CBAERO [16].

Because heating along the trajectory is a limiting factor for heat shields, knowledge about the expected heat loads is essential for design decisions. To estimate heat rates during EDL events a two dimensional code has been written in Matlab. Using a simplified streamline approach this method is capable of 95 approximating the heating during an entire trajectory within a few seconds of computational time. This code is a further development of earlier works that 

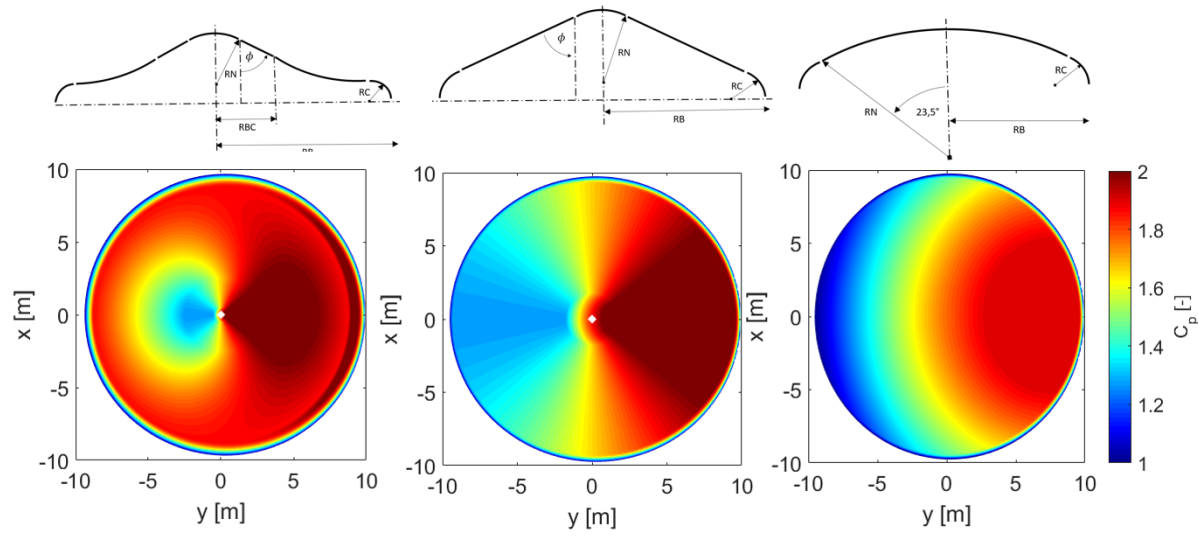

Figure 4: Three dimensional pressure distribution along different heat shield shapes using Newtonian impact theory, Mach 30 and 20 degree AoA.
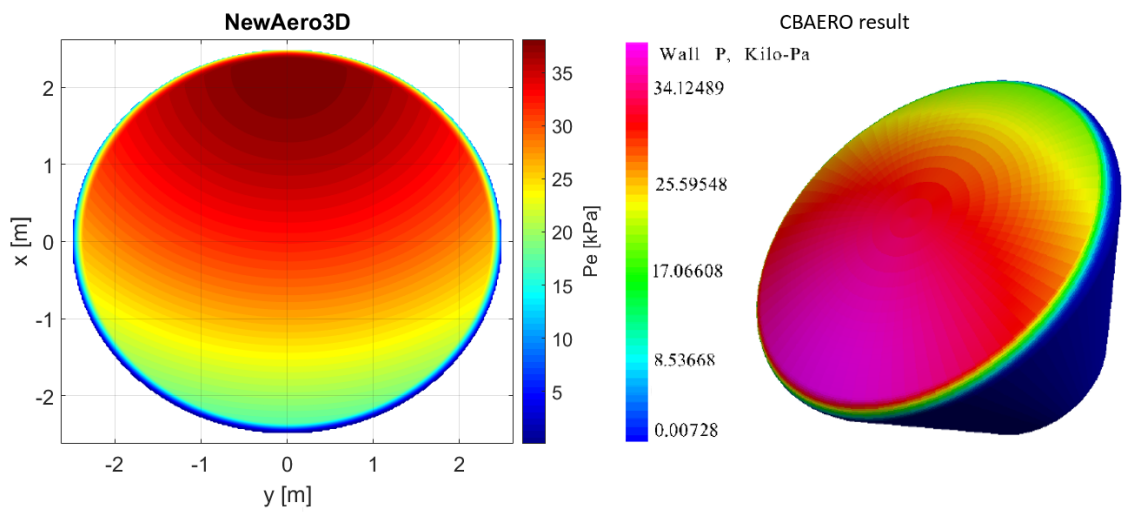

Figure 5: Three dimensional pressure distribution for the Orion lens heat shield, Mach 32.2 and 23 degree AoA, reference from [16].

used the same approach [17. The heat rate is computed along the centerline starting from the stagnation point, as determined by Newtonian flow theory. Although this one dimensional approach to heat-transfer estimation is a significant simplification, it was adapted in order to minimise computational runtime and because maximum heating rates for capsule shaped bodies typically occur along the centerline. Indeed, it can be shown that this method is able to estimate heating within a sufficient accuracy for conceptual design studies, especially in the mostly turbulent leeward area of lifting capsules (See Appendix). 


\section{Reference EDL mission design}

Two reference EDL event sequences are defined to compare results and predict achievable entry masses. These represent a manned and a robotic Mars exploration mission, both of which have fundamentally different demands.

The first reference mission design has been created to fulfil the expected requirements for a manned Mars landing mission and is based on the NASA design reference architecture 5.0 [18. The expected payload is set to 25 respectively 40 tonnes, the maximum reachable landing zone elevation is assumed to be $0 \mathrm{~m}$ with respect to MOLA (Mars Orbiter Laser Altimeter). Further, it is assumed that for this payload class only an atmospheric entry from a stable Mars orbit ${ }_{115}$ is possible. This is in contrast to robotic Mars missions which commonly begin their atmospheric entry maneuver directly from the interplanetary transfer route. This avoids the need for an aerocapture maneuver, but also leads to significantly higher velocities at entry interface. By inserting into an orbit before entering the atmosphere entry velocity can be reduced from approximately $1206 \mathrm{~km} / \mathrm{s}$ to $4 \mathrm{~km} / \mathrm{s}$. Because the maximum heat rate correlates with entry velocities, direct entries lead to a higher burden for heat shields. Early studies using the codes presented earlier have shown that bearable heat rate and heat load limits for flexible heat shield technologies cannot be met within the reachable ballistic coefficient window for a 40 tonne payload with direct entries. Besides entry velocity, the initial flight path angle (FPA) is an important parameter that affects the whole entry design, influencing peak dynamic pressure and heating during EDL events. Figure 6 shows the computed trajectories for four different FPA, overlaid on contours for expected heat rates for different positions on the trajectories. Lower deceleration altitudes corresponding to steeper initial flight path angles result in higher peak heat rates and dynamic pressure peaks. Note that the attainable peak heat rate is a heat shield material property while heat load defines the required heat shield thickness. Furthermore, the heat load decreases with steeper flight path angles. To keep heat shields as lightweight as possible engineers commonly choose steeper FPA options to 
reduce the required material thickness. Because flexible heat shields generally have lower maximum attainable heat rate limits than rigid ones due to flexible thermal protection material constraints, this leads to a situation where shallow FPA's must be considered.

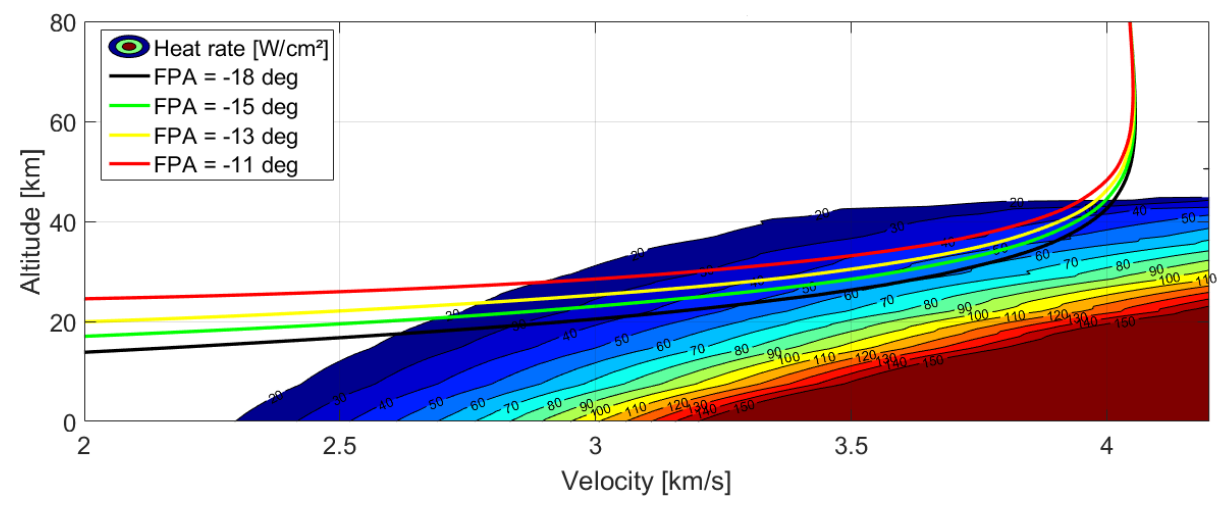

Figure 6: Example trajectory with different initial flight path angles and heat rate contour lines.

Another limiting factor for manned missions is the maximum permissable g-load. A value of $4.5 \mathrm{~g}$ is often imposed to mitigate concerns over the ability of human astronauts to withstand extreme maneuvres after spending several months in micro-gravity [18]. Note that the given g-load limits are derived from medical surveys and are always referred to the average gravitation acceleration on Earth $\left(9.81 \mathrm{~m} / \mathrm{s}^{2}\right)$. To meet the given constraints this analysis has chosen a FPA of $-11^{\circ}$ for all reference designs. This value is relatively shallow compared to past Mars missions [1, 11, 13].

Modern EDL systems utilize aerodynamic forces to maneuver. With an adjustable bank angle the lift vector can be turned leading to a controllable side force. Using bank-control in a so called guided entry the Mars Science Laboratory mission was able to reduce the landing ellipsoid significantly [19]. Bank angle adjustments will have to be provided by EDL systems because landing accuracy will be a driving force for all future Mars missions. Furthermore, the changing bank angle is not negligible for reference event sequence studies 


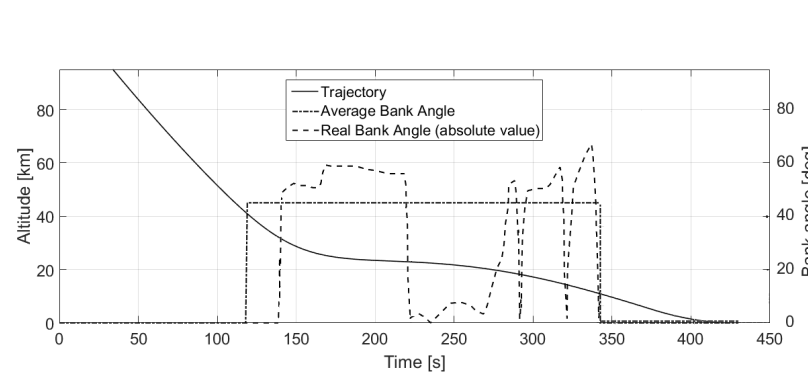

(a) Example bank angle curve along trajectory

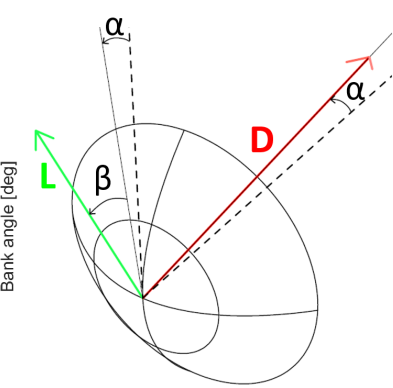

(b) Bank angle definition

Figure 7: Reference Bank angle definition.

because even in a two dimensional analysis the bank angle changes affect the

upward pointing force magnitude. The final bank angle profile is unknown during conceptual design. Therefore it is challenging at this stage to find suitable bank angle profiles. For this study, a simplified, averaged reference bank angle profile is defined consisting of sections of constant bank angles. The idea is to model the loss in upward pointing force within a maneuvering zone by assuming an average bank angle.

Figure 7 shows such an averaged reference bank angle design, compared to the actual bank angle profile and the associated trajectory. One can see that the (averaged) bank angle is initially $0^{\circ}$, which denotes a zone where all the lift is pointed upwards. This first section is necessary to keep the capsule in higher altitudes during the initial deceleration. At lower altitudes, aerodynamic forces increase and a part of lift can be used to maneuver, modeled in this example by an average bank angle of $45^{\circ}$. Note that the object of this modeling is to approximate the final two dimensional trajectory by estimating an averaged bank contour.

In comparison to manned missions, robotic operations have lower payload mass requirements which offers more flexibility for EDL design. A high priority for robotic missions is to offer improvements over present capabilities in terms of increased surface accessibility. Past and present EDL systems for Mars have 
only been able to land in low elevations regions $(<0 \mathrm{~m}$ referred to MOLA)

which makes large areas of the Martian surface inaccessible. Given that high elevation regions are of interest for scientific missions, future EDL designs should be able to deliver robotic probes to a wider range of surface areas and broaden surface accessibility. Considering the lower payload demand, several reference robotic mission designs have been analysed. The reference mission considered in this study is defined to deliver a payload of 2 tonnes to a surface altitude of +5 MOLA $\mathrm{km}$ via direct atmosphere entry from the interplanetary transfer route on a hyperbolic inbound trajectory. The choice of $+5 \mathrm{~km}$ as target elevation is an extreme value considering present capabilities. It was chosen to demonstrate a significantly increased surface accessibility provided by a candidate EDL system. The value of $+5 \mathrm{~km}$ MOLA landing zone elevation is equivalent to a surface accessibility of more than 90 percent [20]. To achieve these goals low ballistic coefficients have to be reached. In this case the design targets BC's between 70 and $120 \mathrm{~kg} / \mathrm{m}^{2}$ to maximize aerodynamic deceleration. Furthermore these designs are able to decelerate at higher altitudes compared to capsules with higher BC's, which increases the descent trajectory distance for the terminal descent system.

\subsection{EDL sequence strategy}

All past and present Mars missions resort to the use of a supersonic DiskGap-Band (DGB) parachute. This technology has served for decades and is

a lightweight and efficient decelerator. Nevertheless it has disadvantages that become more restrictive with increasing payload demands. One problem is the tremendous parachute size required for missions in the 40 tonne payload class: development and verification for such parachutes would be very difficult and expensive. Another disadvantage is that EDL systems have to meet a narrow parachute deployment window, as parachutes only work efficiently in a small Mach and dynamic pressure area and thus additional technologies are usually necessary to decelerate to an acceptable touchdown velocity. For these reasons, we adopt a fundamentally original approach in this study comprising a two 
event sequence with a thrusted terminal descent with ignition in supersonic conditions. This second event uses thrusters for final deceleration and landing. An advantage of this approach is that it is almost arbitrarily scalable and needs a minimum of reverification after payload adjustments. It is a highly flexible combination with the capacity to provide a platform for a broad payload range. The potential of this approach has recently been demonstrated by the Falcon 9 program, which showed that the technology exists to decelerate and land heavy vehicles from supersonic conditions using rocket thrusters.

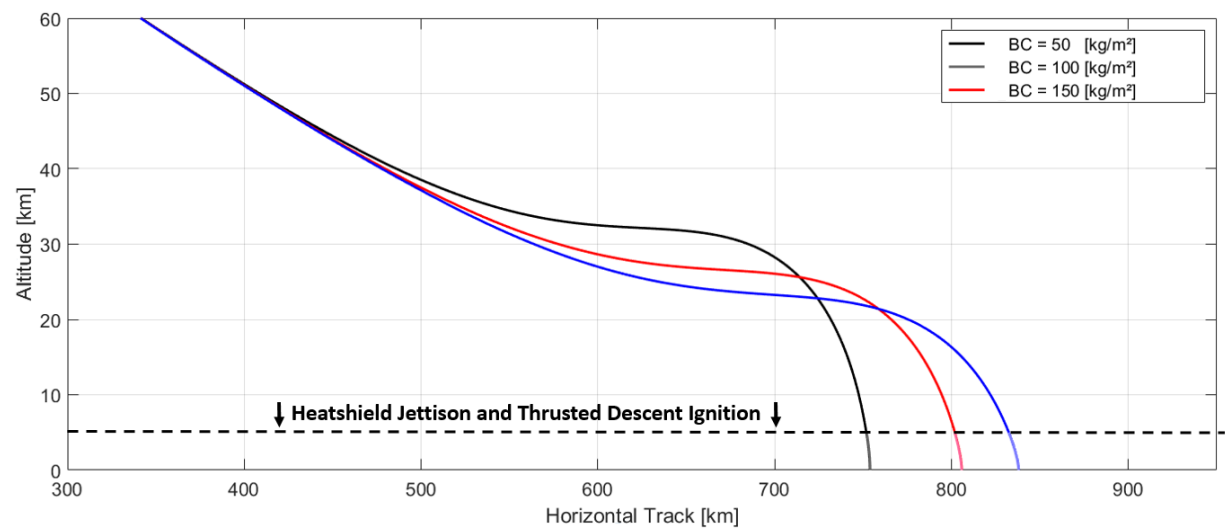

Figure 8: Reference EDL event sequence trajectories for different ballistic coefficients.

Figure 8 shows the chosen two event EDL sequence comprising an initial phase utilising a fully deployed flexible heat shield and a second phase using thrusters to decelerate and land. The flexible heat shield deployment would take place prior to the start of the EDL operation, so that during the entire entry maneuver the maximum drag area is available. Actuation loads would also be minimized this way, resulting in lighter structures.

Table 1 shows an overview of the presented reference trajectories for robotic and human Mars missions that are considered in the following analysis. The human Mars mission reference designs $T_{-} H_{-} B_{-} 1$ and $T_{-} H_{-} B_{-} 2$ use an identical event strategy. $T \_H \_B \_2$ is added to show the effect of lower payload demands and to compare results with other studies [21] $T_{\_} H_{-} B_{\_} 3$ is the reconstructed 
Table 1: Reference trajectories overview.

\begin{tabular}{lccccc}
\hline Trajectory & Payload & BC & Initial FPA & $\mathbf{V}_{\text {in }}$ & $\begin{array}{c}\text { Landing zone } \\
\text { elevation } \\
{[\mathrm{m}]}\end{array}$ \\
\hline \hline T_H_B_1 (human) & 40000 & $50-600$ & -11 & 4000 & 0 \\
T_H_B_2 (human) & 25000 & $50-600$ & -11 & 4000 & 0 \\
T_H_B_3 (human) & 25000 & $50-600$ & -14.5 & 4900 & 0 \\
\hline T_R_B_1 (robotic) & 2000 & $25-300$ & -14 & 6000 & +5000 \\
\hline
\end{tabular}

EDL maneuvre of [21] with a higher entry velocity (entry from highly elliptical orbit) and steeper initial flight path angle. Note that for robotic missions a flight path angle of 14 degrees is chosen. For the robotic class, g-load limits are far less restrictive than for human missions which would allow the choice of a steeper initial entry path. Since the main deceleration should take place in altitudes as high as possible for this study to reach high elevation landing zones a comparatively shallow initial flight path angle has been chosen for this mission type.

\section{Mass estimation methodology}

A novel methodology has been developed for this analysis to compare reference EDL designs and heat shield technologies. The concept uses mass correlations to relate heat shield masses directly to achievable entry masses. The following method should diminish system complexity and reduce conceptual design problems to key parameters in order to simplify the search for optimal EDL strategies in the Martian atmosphere.

The overall entry mass is estimated using a break-down into individual subsystems. To estimate the required system mass for a given payload several mass correlations from [22] were used. 
For support structure and back-shell, the following empirical relations were used:

$$
\begin{aligned}
& m_{\text {structure }}=\left[\begin{array}{ll}
0.0232 & q_{\text {max }}^{0.1708}
\end{array}\right] m_{0} \\
& m_{\text {backshell }}=0.14 m_{0}
\end{aligned}
$$

where $q_{\max }$ is the maximum dynamic pressure and $m_{0}$ the initial entry mass. The reaction control system (RCS) mass is determined as follows.

$$
\begin{aligned}
m_{\text {engine }, R C S} & =0.005 m_{0} \\
m_{\text {prop } / \operatorname{tank}, R C S} & =0.0101 m_{0}
\end{aligned}
$$

The terminal descent system (TDS) is an important subsystem for mass estimation. To approximate the system mass the following correlations were applied:

$$
\begin{aligned}
m_{\text {engine }, T D S} & =0.00144 T_{\text {max }}+49.6 \\
m_{\text {tank }} & =\frac{P V}{g_{0} \phi_{\text {tm }}} \\
m_{\text {fuel }} & =\frac{M_{\text {fuel }, T D S}}{O / F+1} \\
m_{\text {ox }} & =O / F m_{\text {fuel }}
\end{aligned}
$$

where $T_{\max }$ is the maximum thrust, $P$ the tank pressure, $V$ the tank volume and $\phi_{t m}$ the material factor of the tank material. $\phi_{t m}$ is set to $5000 \mathrm{~m}$ which is valid for titanium tanks. $\mathrm{O} / \mathrm{F}$ is the fuel to oxidizer ratio. $M_{f u e l, T D S}$ denotes the overall fuel mass and is defined as:

$$
M_{f u e l, T D S}=m_{o x}+m_{f u e l}
$$

Applying the presented correlations several substructure classes can be defined:

$$
\begin{aligned}
m_{0} \sum m_{f, \text { substrucutre }} & =m_{0}\left[\left[0.0232 q_{\max }^{0.1708}\right]+[0.14]+[0.005]+[0.0101]\right] \\
\sum m_{T D S} & =m_{\text {engine }, T D S}+m_{\text {tank }, T D S}+m_{f u e l}+m_{\text {ox }}
\end{aligned}
$$

where $\sum m_{f, \text { substrucutre }}$ is the sum of subsystem components mass fractions as they are defined in equations 15 to 18 Using these classes, the entry mass $m_{0}$ 
can be written as:

$$
m_{0}=m_{0} \sum m_{f, \text { substrucutre }}+\sum m_{T D S}+m_{0} m_{f, \text { heatshield }}+m_{\text {payload }}
$$

and can be transformed to:

$$
m_{0}=\frac{m_{\text {payload }}+\sum m_{T D S}}{1-\sum m_{f, \text { substructures }}-m_{f, \text { shield }}}
$$

where the heat shield mass fraction $m_{f, \text { shield }}$ is defined as:

$$
m_{f, \text { shield }}=\frac{m_{\text {heatshield }}}{m_{0}}
$$

A new variable can be introduced to simplify the interpretation of results. The heat shield area density $\Phi_{\text {shield }}$ describes the heat shield mass in relation to the provided projected surface area:

$$
\Phi_{\text {shield }}=\frac{m_{\text {heatshield }}}{A_{\text {proj }}}=\frac{m_{f, \text { shield }} m_{0}}{2 \pi R B^{2}}
$$

$\Phi_{\text {shield }}$ is an essential technology property that depends on the design and architecture of a given heat shield and is assumed to be independent of scaling, at least over the range of heat shield sizes necessary for the missions considered in this study. $\Phi_{\text {shield }}$ is therefore a powerful tool to describe the efficiency of different heat shield technologies. In the following evaluation this parameter will play an important role to illustrate results.

Using equations 1 and 29 the heat shield mass fraction can be written as:

$$
m_{f, \text { shield }}=\frac{\Phi_{\text {shield }}}{B C C_{d}}
$$

where $C_{d}$ is an average drag coefficient value along the trajectory and has to be estimated. With this expression equation 27 can be transformed to:

$$
m_{0}=\frac{m_{\text {payload }}+\sum m_{T D S}}{1-\sum m_{\text {substructures }}-\frac{\Phi_{\text {shield }}}{B C C_{d}}}
$$

Because the TDS mass is an indirect function of $m_{0}$, equation (31) has to be solved iteratively. The trajectory code presented in the previous section is used to determine the TDS fuel mass. 


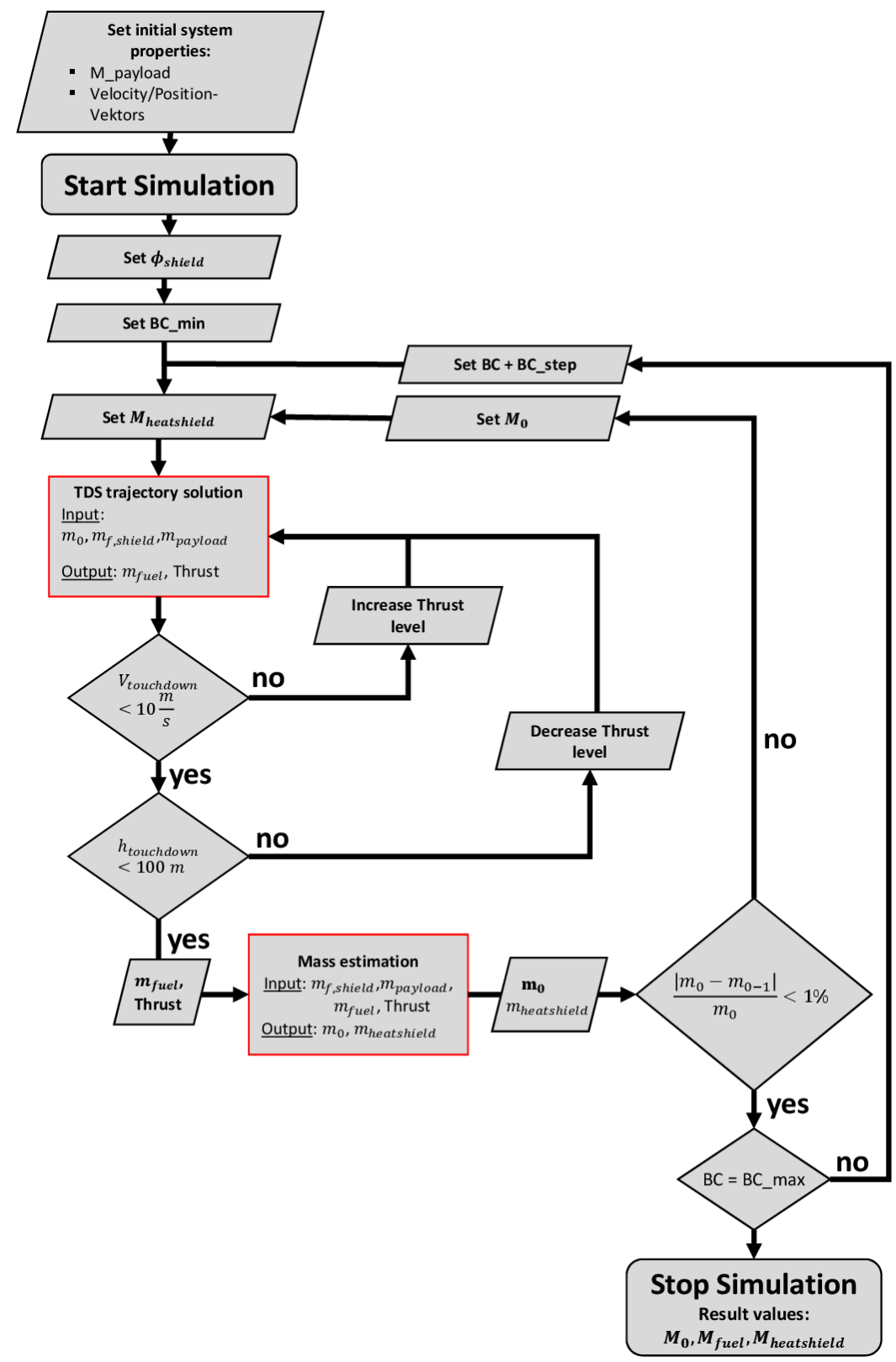

Figure 9: Iterative approach to compute $m_{0}$.

Figure 9 shows the iterative approach to calculate the entry mass for a given heat shield area density $\Phi_{\text {shield }}$. By applying this method for an array of $\Phi_{\text {shield }}$ 
a curve can be generated that shows the trend of entry mass with increasing $\Phi_{\text {shield}}$. The approach illustrated in figure 9 allows the problem to be tackled in two ways: Either with a fixed BC and Variable $\Phi_{\text {shield }}$ or with a fixed $\Phi_{\text {shield }}$ and a variable $\mathrm{BC}$. Both solutions will be presented and discussed in the following analysis.

Figure 10 shows the results achieved with method 1 (fixed BC and Variable $\left.\Phi_{\text {shield }}\right)$ for two example trajectories for human Mars missions, both with a payload of 40 tonnes but with different BC's of 50 and $300 \frac{\mathrm{kg}}{\mathrm{m}^{2}}$. To assess compatibility with available launcher architectures a line of maximum launch weight is shown: a maximum payload launch capability to LEO of 130 tonnes is based on predictions for SLS Block II [23. Note that this assumption implies a second launch for the interplanetary propulsion stage that would be necessary for a mission to Mars. Figure 10 shows a direct connection between average heat shield density $\Phi_{\text {shield }}$ and achievable mass and thus enables a rapid assessment of mission feasibility.

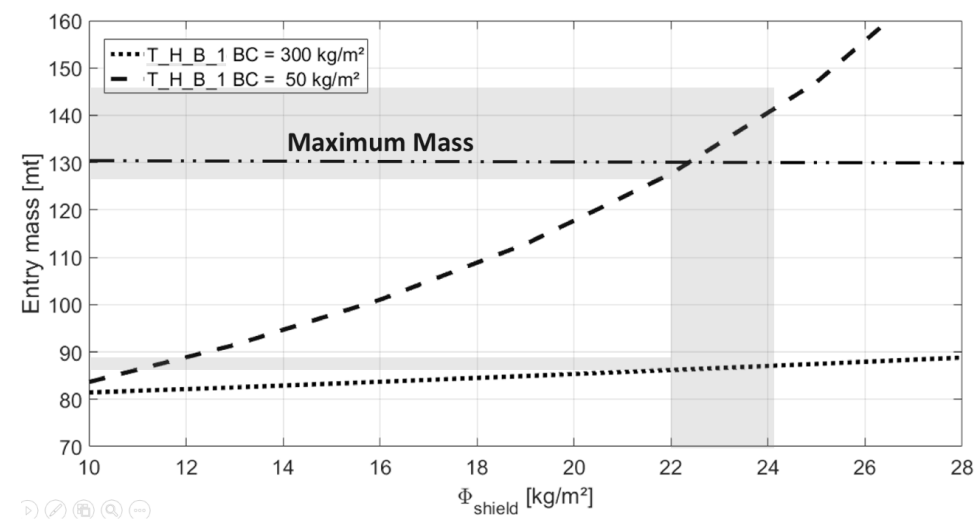

Figure 10: Achievable entry masses for manned mission reference designs and a payload of 40 tonnes.

Further, this presentation facilitates comparison of the performance of different reference strategies with regard to mass efficiency. In this example it can be seen that selection of a higher BC yields lower entry masses and therefore more mass efficient options. The graph also shows the sensitivity of entry mass 
to heat shield mass changes. It can be seen, that low ballistic configurations are more sensitive to mass changes (represented in this graph by changes in $\Phi_{\text {shield }}$ ) than high BC alternatives.

\section{Supersonic retro-propulsion modeling}

As mentioned earlier, selection of a fully thrusted terminal descent system (TDS) is a fundamental new element in event sequence design compared to previous missions. Within this modeling, the TDS plays a significant role as computed entry masses are driven by the fuel mass needed for the terminal descent. Previous simulations have shown that computed entry masses can be sensitive to changes in TDS efficiency. However, for this analysis a simplified model to compute thrust requirement and fuel consumption has been applied, with TDS efficiency described by a specific impulse (ISP) value. Since ignition takes place in supersonic conditions and landing occurs at velocities close to zero it can be expected that a change in ISP occurs during the trajectory and engines are not firing with maximum efficiency at any point. Given a lack of data about ISP changes for retro-propulsive systems from supersonic to subsonic conditions, this analysis uses an average ISP which is assumed to be constant during the descent. The specific impulse can be written as:

$$
I S P=\frac{T}{g_{0} \dot{m}}
$$

The thrust profile $\mathrm{T}$ can be chosen arbitrarily as long as the touchdown velocity is reached. The required fuel mass can be computed as follows:

$$
m_{\text {fuel }}=\int_{\text {ignition }}^{\text {touchdown }} \frac{T}{g_{0} I S P} d t
$$

Using an averaged ISP value, ISP becomes a property determined by the choice of the fuel/oxidizer combination. For safety and cost reduction reasons, MMH/NTO would be a suitable combination for terminal descent systems today. However, many authors assume that Methane/LOX will be the 
back of peak thrust requirement and the possibility of disturbing the Martian surface and raising dust.
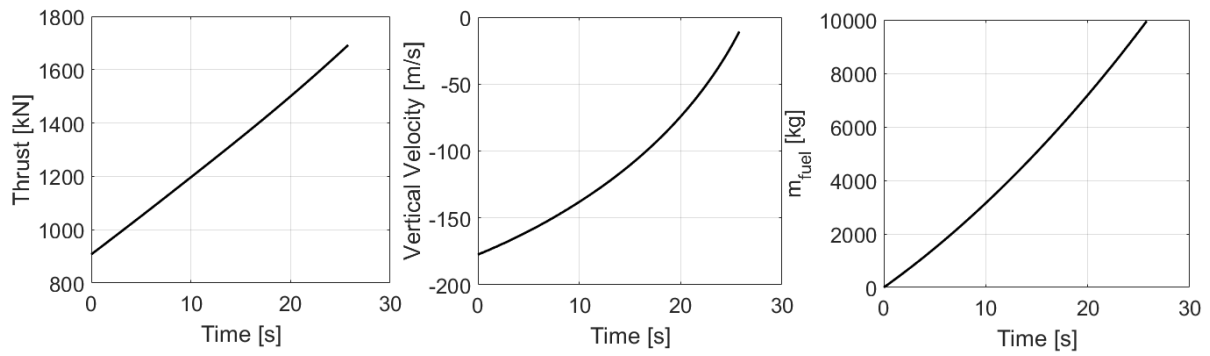

Figure 11: Computed values for the SRP maneuver of a high payload Mars EDL mission.

\section{Weight and sizing of promising heat shield technologies}

As mentioned earlier $\Phi_{\text {shield }}$ is a heat shield technology property that is asheat shield demonstrators calls this assumption into question as these demonstrators have shield diameters between 1 and 3 meters whereas the required diameters of a 40 tonne payload lander for Martian atmosphere is likely to be in the range of 18 to $25 \mathrm{~m}$. Hence, the small scale demonstrators may not possess

realistic $\Phi_{\text {shield }}$ and a more fundamental approach of estimating this parameter 
for deployable and inflatable architectures is required

A inflatable heat shield provides a solid area by inflating several tubes. On the outside, the tubes are protected by a flexible heat shield coat. Such devices are commonly referred as hypersonic inflatable aerodynamic decelerators (HIAD) due to the fact that they utilize a fully deployed shield during the whole entry maneuver. In contrast, mechanically deployable heat shields supply an increase in surface area by extending several ribs with a flexible heat shield coat, much like an umbrella.

Figure 12: $\Phi_{\text {shield }}$ estimation for large area flexible shields.

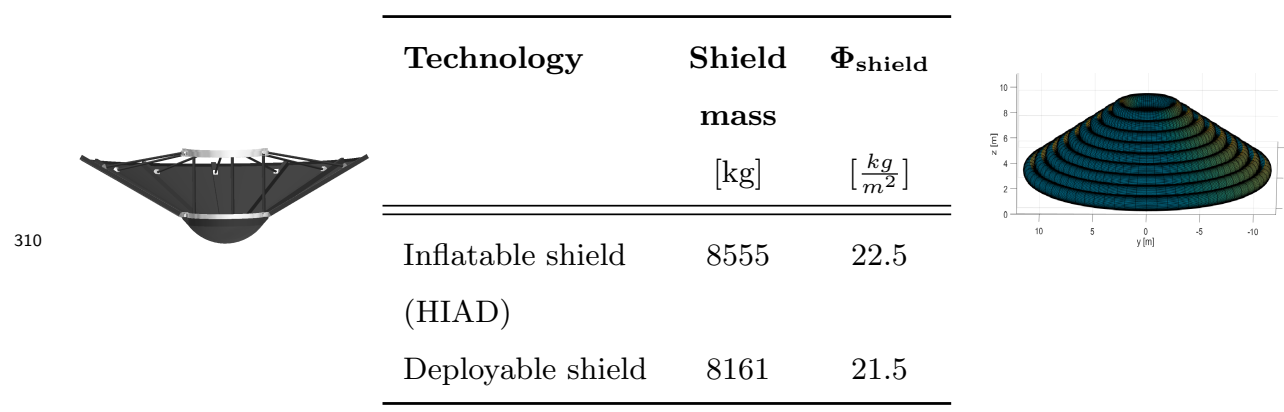

To estimate $\Phi_{\text {shield }}$ values for large area shields of both technologies, CAD models for both options have been developed. These large area models are similar to smaller technology demonstrators but take influences of scaling into account. The inflatable model is largely based on the IRVE [25] demonstrator, while the large area deployable shield CAD model has been developed based on the ADEPT [26] design. Table 12 shows estimated values for $\Phi_{\text {shield }}$ for both of these two. One can notice that estimated masses for both technology alternatives are very similar and correspond to mass efficiencies of 22 to $23 \frac{\mathrm{kg}}{\mathrm{m}^{2}}$. The value of $23 \frac{\mathrm{kg}}{\mathrm{m}^{2}}$ is used for $\Phi_{\text {shield }}$ in the following analysis of human and robotic Mars missions.

\section{Mission analysis: human Mars mission}

Given a value of $\Phi_{\text {shield }}$ (determined by system architecture), an optimal BC in terms of minimized entry mass can be found. To qualify flexible shield results this survey aims to compare given outcomes to an approach using a high BC entry. Price, 
Manning, Sklyanskiy and Braun 21] recently proposed a radical departure from conventional EDL mission strategies with a concept to adopt a high BC initial entry of $600 \frac{\mathrm{kg}}{\mathrm{m}^{2}}$ combined with a SRP maneuver as final event. The authors claim that approach facilitates the use of a rigid heat shield (of approximately $10 \mathrm{~m}$ in diameter) for entry masses up to approximately 70 tonnes. This claim is in good agreement with the results shown in figure 1 The use of a solid heat shield affords a value of $\Phi_{\text {shield }}$ in the region of $11 \frac{\mathrm{kg}}{\mathrm{m}^{2}}$ based on values from past Mars missions. This reduction over the value of $23 \frac{\mathrm{kg}}{\mathrm{m}^{2}}$ for flexible heat shields is primary due to the significantly lower complexity of a rigid shield design. Figure 13 shows a comparison between a large area CAD mock-up using a flexible heat shield and the rigid shield proposal from [21]. The version on the left was designed for a payload of 40 tonnes and a shield diameter of $22 \mathrm{~m}$ (deployed) whereas the rigid shield alternative on the right is created for a payload of 25 tonnes and a shield diameter of $10 \mathrm{~m}$.
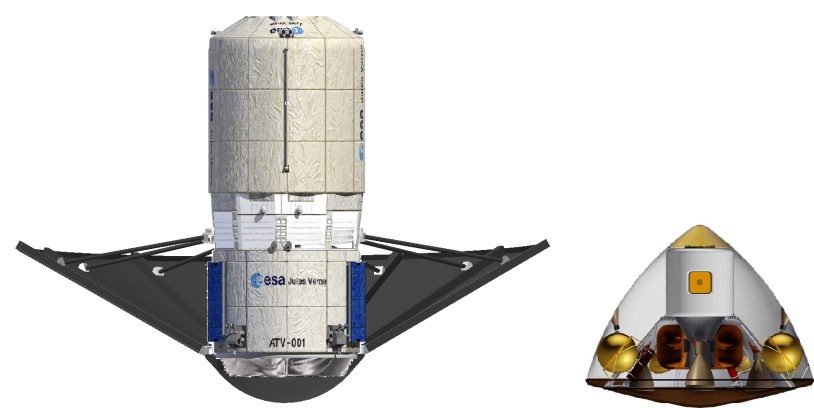

Figure 13: Large area extendible shield (left) and high $\mathrm{BC}$ rigid shield (right) 21.

A major strength of the methodology adopted in this study is that it enables comparison of mission designs with different $\Phi_{\text {shield }}$ and payloads. Hence for each viable technology (with an associated $\Phi_{\text {shield }}$ ) an optimum BC exists in terms of entry mass efficiency.

Figure 14 shows the variation of entry mass with BC for a two event entry using a flexible heat shield $\left(\Phi_{\text {shield }}=23 \frac{\mathrm{kg}}{\mathrm{m}^{2}}\right)$ and a solid heat shield $\left(\Phi_{\text {shield }}=11 \frac{\mathrm{kg}}{\mathrm{m}^{2}}\right)$. To compare results both strategies are computed for a payload mass of 25 tonnes. For a BC of $600 \frac{\mathrm{kg}}{\mathrm{m}^{2}}$, the solid shield $\left(\Phi_{\text {shield }}=11 \frac{\mathrm{kg}}{\mathrm{m}^{2}}\right)$ yields an entry mass of approximately 64 tonnes. Further, it can be shown that the high BC is in fact not the most mass efficient solution. In this case the choice of $\mathrm{BC}$ is driven by the need to combine as 
much payload mass with a given maximum launchable diameter which is the restrictive parameter for solid shields. As it can be seen this compromise is not the optimum in terms of mass efficiency, which actually occurs for much lower BC's of around $140 \frac{\mathrm{kg}}{\mathrm{m}^{2}}$.

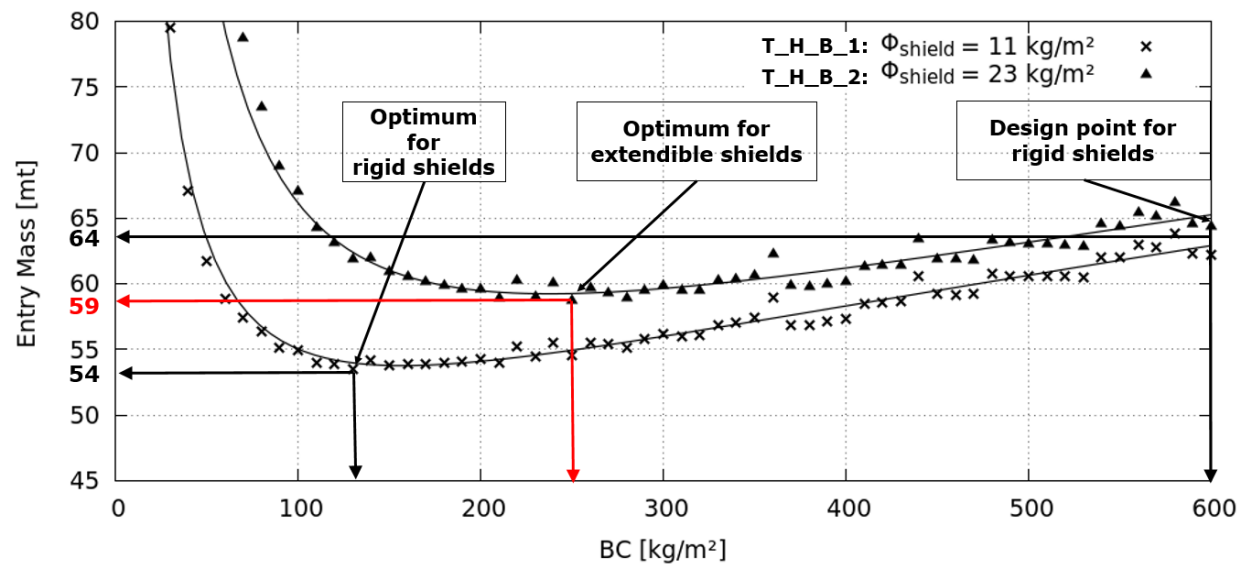

Figure 14: Entry mass for different ballistic coefficient vehicles and a payload of 25 tonnes (reference trajectory T_H_B_2).

Figure 14 also shows that the optimum for a flexible heat shield $\left(\Phi_{\text {shield }}=23 \frac{\mathrm{kg}}{\mathrm{m}^{2}}\right)$ occurs at a BC of $250 \frac{\mathrm{kg}}{\mathrm{m}^{2}}$ which is higher than that for solid ones $\left(\Phi_{\text {shield }}=11 \frac{\mathrm{kg}}{\mathrm{m}^{2}}\right)$ as a consequence of the higher shield weight. Both curves on figure 14 illustrate how combining SRP with a high BC entry maneuvre results in lower mass efficiencies due to the increasing velocity difference that has to be provided by the TDS. The connection between TDS ignition velocity and TDS mass fraction can be seen in figure 15 . Within the presented modeling the TDS mass scales with the velocity difference that has to be provided by the system. Further on it is the characteristic of the modeling that with a fixed ignition altitude the ignition velocity is a depending on the BC. Hence the resulting velocity curve is not depending on $\Phi_{\text {shield }}$. Also the link between capsule diameter and heat shield mass fraction can be seen. The hyperbolic character leads to the significant entry mass increase for very low BC strategies.

Flexible heat shield technology thus offers the possibility to increase mass efficiency and payload mass fractions especially for high payload Mars missions. The analysis shows that especially in a thin atmosphere it can be beneficial to invest in efficient aerodynamic decelerators (low BC solutions for the initial phase) instead of high BC designs which require a high velocity difference for the TDS. By removing a constraint 

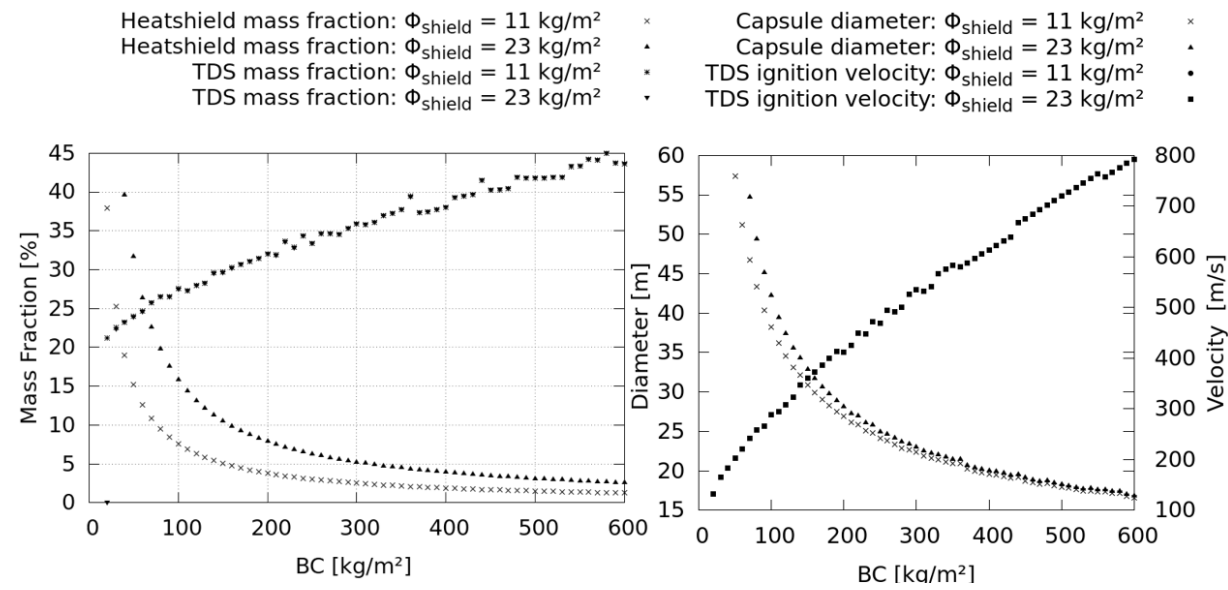

Figure 15: Capsule diameter and TDS ignition velocity compared to heatshield and TDS mass fraction.

on maximum shield diameter and hence minimum BC, they offer an opportunity to design and optimize entry vehicles more freely and realise their full potential in a complete EDL system design. Furthermore, flexible heat shield technology offers not only improvements in optimization for conventional missions but also enables EDL concepts with a significantly increased payload mass range. This is in contrast to solid shield designs where even a high $\mathrm{BC}=600 \frac{\mathrm{kg}}{\mathrm{m}^{2}}$ yields a maximum entry mass of approximately 70 tonnes given near future launcher capabilities. Further payload increase is not possible with a solid shield (see figure 1), whereas extendible shields offer the capability of being scaled up to facilitate a delivery of higher payloads to the Martian surface.

Figure 16 shows a comparison of predicted entry mass for two mission architectures: a payload mass of 40 tonnes combined with a flexible shield (T_H_B_1) and a payload mass of 25 tonnes combined with a solid shield (T_H_B_3). For a BC of $250 \frac{\mathrm{kg}}{\mathrm{m}^{2}}$ and a payload of 40 tonnes an entry mass of approximately 94 tonnes is necessary, whereas the solid shield option with a BC of $600 \frac{\mathrm{kg}}{\mathrm{m}^{2}}$ and a payload of 25 tonnes achieves an entry mass of 75 tonnes, which is in good agreement to the system mass estimated in 21.

Thus a rise of payload mass of almost 38 percent can be achieved with an increase in entry mass of just 25 percent changing from a solid to a flexible shield design. This example illustrates the considerable potential of flexible heat shield technology for 

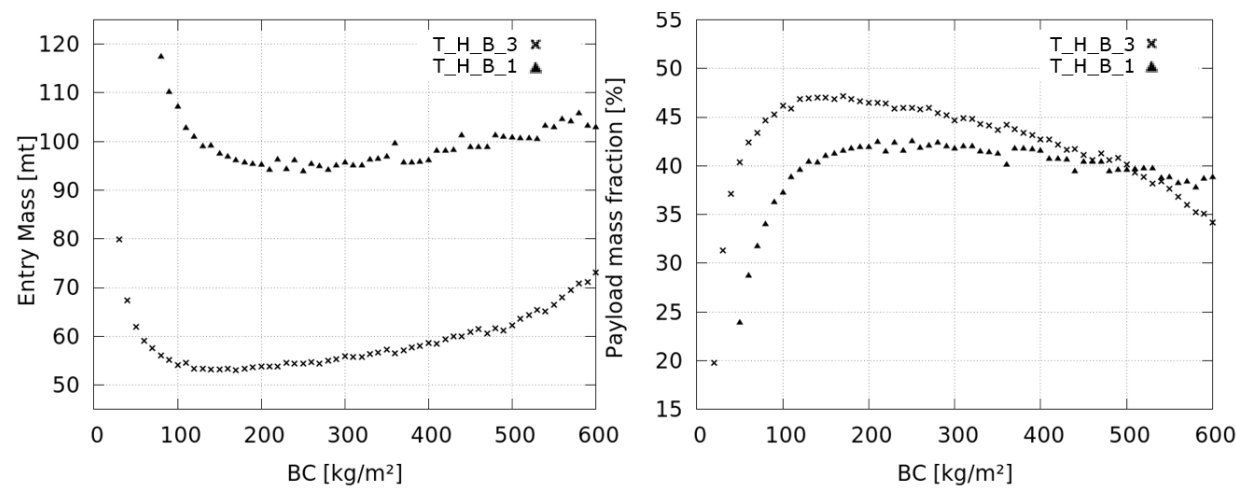

Figure 16: Comparison between extendible heat shield design $T_{-} H_{-} B_{-} 1\left(\Phi_{\text {shield }}=23 \frac{\mathrm{kg}}{\mathrm{m}^{2}}\right.$, $\left.m_{\text {payload }}=40 \mathrm{mt}\right)$ and rigid shield $T_{-} H_{-} B \_3\left(\Phi_{\text {shield }}=11 \frac{\mathrm{kg}}{\mathrm{m}^{2}}, m_{\text {payload }}=25 \mathrm{mt}\right)$.

planetary missions with significant payload demands. Furthermore figure 16 shows the computed payload mass fractions for both strategies. Unsurprisingly, higher payload mass fractions can be achieved over a wide range of $\mathrm{BC}$ utilising the more lightweight heat shield technology. However, it is important to keep in mind that for rigid shields only the $\mathrm{BC}=600 \mathrm{~kg} / \mathrm{m}^{2}$ option is feasible due to launch vehicle fairing diameter constraints.

The challenge of design and optimization of EDL systems is that many parameters have to be considered. Whilst mass efficiency has been the main focus of this study so far, it is prudent to consider additional aspects to ensure mission feasibility.

Table 2: Maximum g-load during the EDL phase for different reference trajectories.

\begin{tabular}{|c||c|c|c|c|c|}
\hline BC [ $\left.\frac{\mathrm{kg}}{\mathrm{m}^{2}}\right]$ & 50 & 100 & 200 & 300 & 600 \\
\hline Peak g-load [ $\left.\frac{\mathrm{m}}{\mathrm{s}^{2}}\right]$ & 3.87 & 3.67 & 3.48 & 3.20 & 4.15 \\
\hline
\end{tabular}

Table 2 shows the maximum g-load for different BC reference trajectories. It can be seen that maximum deceleration generally decreases with increasing BC with the exception of $\mathrm{BC}=600 \frac{\mathrm{kg}}{\mathrm{m}^{2}}$ where a peak in g-load during the SRP maneuver is encountered. Figure 17 illustrates this effect by means of three example trajectories with different ballistic coefficients. It can be seen that the $\mathrm{BC}=600 \frac{\mathrm{kg}}{\mathrm{m}^{2}}$ requires a stronger deceleration by the SRP maneuvre as a consequence of the higher ignition velocity and lower ignition altitude. Furthermore, it can be noted that all presented 
alternatives are below accepted limits $(4.5 \mathrm{~g})$ for manned space flight.
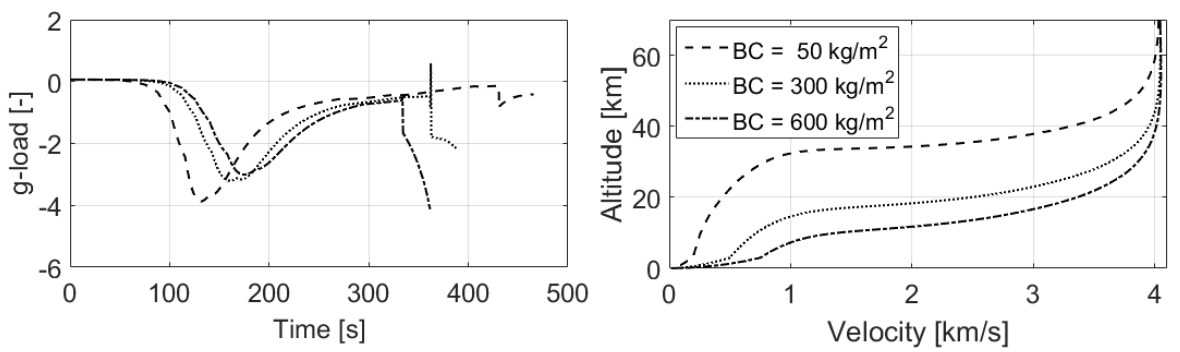

Figure 17: Normalized deceleration and entry trajectories for Ballistic Coefficients of 50, 300 and $600 \mathrm{~kg} / \mathrm{m}^{2}$. 


\section{Mission analysis: robotic Mars mission}

405 to combine modest payload increases with greatly extended surface accessibility. The presented trajectories for robotic missions typically skip aerocapture maneuvers and instead turn directly from their interplanetary transfer route into an EDL maneuver in the Martian atmosphere.

410 $\left(T_{-} R_{-} B_{-} 1\right)$ described in table 1 The optimum $\mathrm{BC}$ region is flatter compared to results for manned missions in the previous section, which suggests entry mass is relatively insensitive to $\mathrm{BC}$ for lower payload demands. However, at low $\mathrm{BC}$ configurations (BC $\left.=100 \frac{\mathrm{kg}}{\mathrm{m}^{2}}\right)$ a hyperbolic increase in entry mass is observed due to the significantly higher shield mass causing a considerably inefficiency. With lighter shield materials $\left(\Phi_{\text {shield }}<23 \frac{\mathrm{kg}}{\mathrm{m}^{2}}\right.$ ) ultra low BC strategies could become feasible, but with present technology the evaluation showed that for this mission type the chosen BC should not be less than $60 \frac{\mathrm{kg}}{\mathrm{m}^{2}}$ to optimize mass efficiency. The model predicts further that with a BC of approximately $200 \frac{\mathrm{kg}}{\mathrm{m}^{2}}$ a lander utilising flexible heat shield technology and

side with a surface elevation of of $+5000 \mathrm{~m}$ with respect to MOLA.

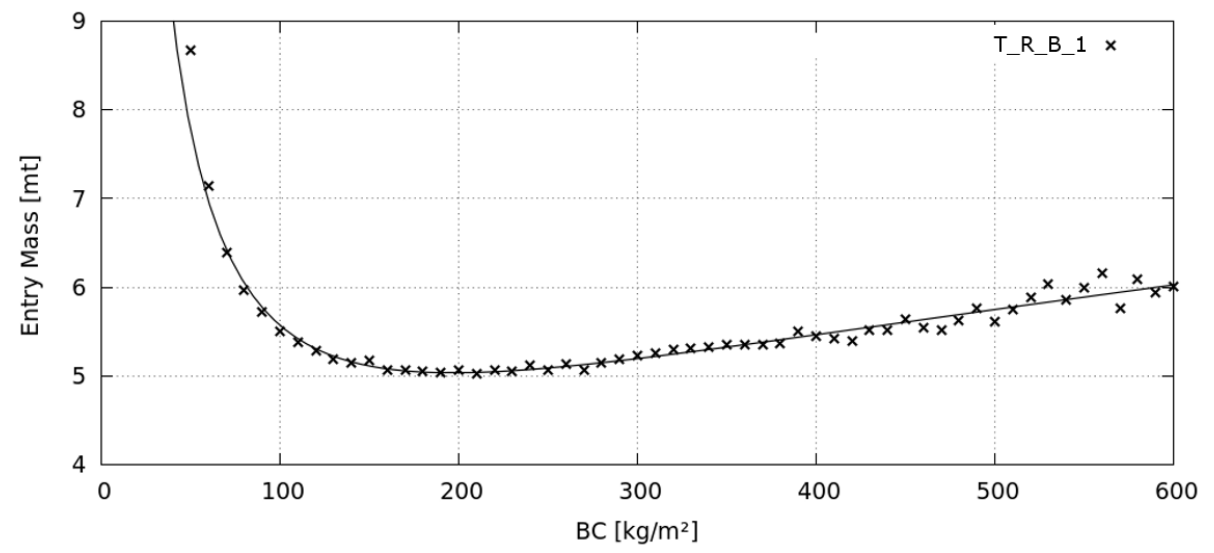

Figure 18: Variation of entry mass with ballistic coefficient:

$\Phi_{\text {shield }}=23 \frac{\mathrm{kg}}{\mathrm{m}^{2}}, \quad \mathrm{~m}_{\text {paylod }}=2$ tonnes, $\quad$ FPA $=-11$ degrees, $\quad v_{\text {in }}=6000 \frac{\mathrm{m}}{\mathrm{s}}$, landing zone elevation $=+5000$ MOLA $\mathrm{m}$. 


\section{Conclusion}

Future Mars missions impose high demands on engineers to push existing and candidate technologies to their limits. In the field of EDL system design, an expansion of present capabilities is required to meet these demands. The methodology presented here offers a valuable tool for analysis and evaluation of fundamentally new EDL designs and ultimately allows the identification of trends and optima to guide event sequence selection as well as lander design.

The developed methodology has been applied to a reference manned mission and has demonstrated that flexible heat shield technology has the potential to surpass solid shield designs. The use of a solid heat shield is fundamentally limited in maximum payload to around 25 tonnes by available launcher structures ( $10 \mathrm{~m}$ diameter). In contrast, flexible heat shields offer the potential to bring 40 tonnes (or more) of payload to the Martian surface. This conclusion is all the more remarkable given that flexible shields are assumed to be twice as heavy as solid ones. The construction of flexible shields offers more freedom in design that can be used to compensate the weight disadvantage. Moreover, it could be shown that benefits can be used to increase the EDL system's mass efficiency and payload mass fraction. At a conceptual level the methodology illustrates how different EDL systems require different BC for optimal mass efficiency.

This analysis relies on the use of supersonic retro-propulsion as a viable candidate for terminal descent system design, as previous simulations have confirmed. In combination with extendible heat shields, SRP offers to build a technology platform that can serve for decades in planetary landing missions like the Viking heritage did for more than 40 years. This combination appears to be freely scalable, making it equally applicable and suitable for small planetary probes as well as large manned landers and cargo missions. Projects on Earth have already shown operability and capability of SRP using high thrust rocket engines and heavy landers. The technology is ready to be applied to planetary landing systems. 


\section{Appendix}

The code to approximate heating during the entry maneuver has been validated with different CFD and test results. To show agreement and illustrate the achievable accuracy some examples are shown below. The presented code is able to calculate heating with or without having regard to the effect of an entropy layer. The resulting outputs are shown in green respectively red. Figure 19 shows the two dimensional results (along the capsule's centerline) for specific trajectory point (fixed velocity, altitude and atmosphere properties). Figure 20 shows peak heating results along an entire trajectory.

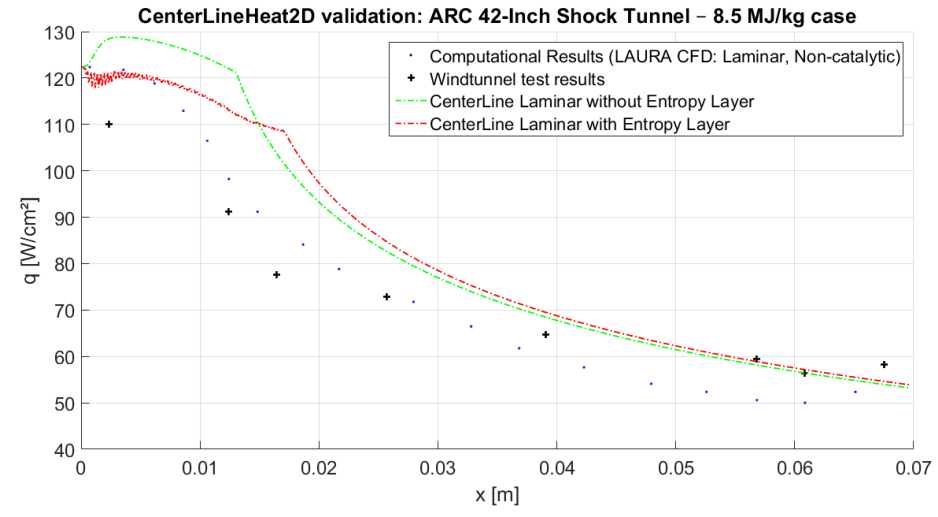

Figure 19: CenterLineHeat Validation - Non lifting wind tunnel test with CFD results, reference data from [27].
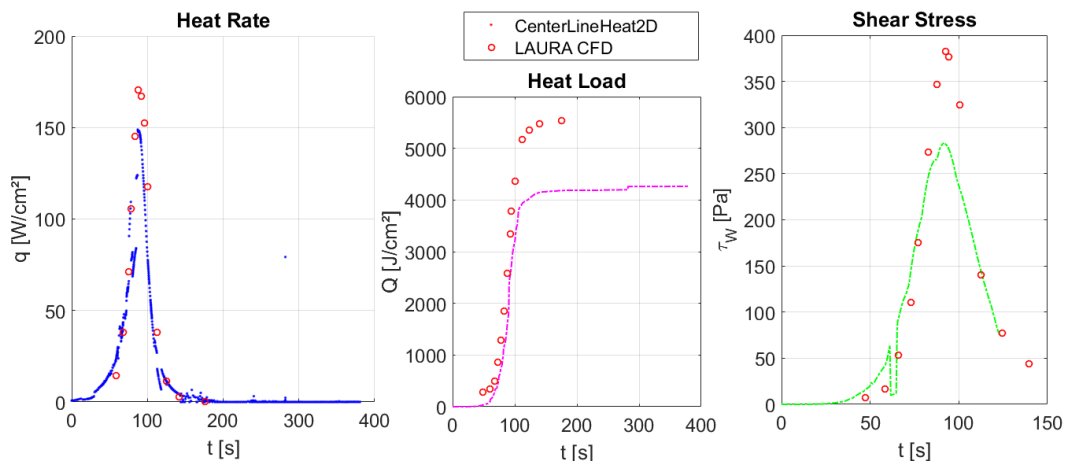

Figure 20: CenterLineHeat Validation - Lifting entry for the 08-TPS-01a-design trajectory (Mars Science Laboratory), reference data from 28. 
As it can be seen the method is capable to predict the peak heat rate for the MSL trajectory with a sufficient accuracy (12 percent deviation). Unfortunately the heat load could not be acquired with a similar accuracy. Hence for this study it is not yet possible to implement a function that adapts the heat shield thickness according to the predicted heat loads. The presented study works with a constant heat shield thickness (oriented on proposals for IAD demonstrators and the MSL shield) independent from the respective heat load which would not be the case for a real mission. Nevertheless it is a reasonable simplification considering the fact the expected heat loads for all presented reference trajectories are in the range of previous mentioned information sources. 


\section{Acknowledgements}

The first author would like to thank Technische Universität München and Imperial

College London for their ERASMUS programme which made this research program possible. All authors would like to thank Ms. Lisa Peacocke for her ideas and suggestions that helped drive this project forward.

\section{References}

[1] Robert M. Manning Robert D. Braun. "mars exploration entry, descent and landing challenges", 2007.

[2] Chris J. Cerimele Jarret M. Lafleur. "mars entry bank profile design for terminal state optimization", 2008.

[3] Mark Schoenenberger Karl T. Edquist, Prasun N. Desai. "aerodynamics for the mars phoenix entry capsule", 2011.

[4] NASA Mars Architecture Steering Group Bret G. Drake. "human exploration of mars design reference architecture 5.0", 2009.

[5] Michelle M. Munk. "overview of the nasa entry, descent, and landing systems analysis (edl-sa)", 2010.

[6] Arianespace. "ariane 5 - users manual", 2011.

[7] United Launch Alliance. "atlas v launch services users guide". United Launch Alliance, 2010.

[8] National Aeronautics and Space Administration. "space launch system (sls) program mission planners guide (mpg) executive overview". SLS-MNL-201 VERSION 1, 2014.

[9] Paul Wercinski Dr. Peter Gage. "adaptable, deployable entry technology and placement (adept) project". Presentation, IPPW10 EDL Short Course. American Institute of Aeronautics and Astronautics, 2013.

[10] National Aeronautics and Space Administration. "game changing development hypersonic inflatable aerodynamic decelerator (hiad)". NASA facts Technology Paper, 2014. 
[11] Robert D. Braun Soumyo Dutta. "statistical entry, descent, and landing performance reconstruction of the mars science laboratory". Journal of Spacecrafts and Rockets, Vol. 51, No. 4, 2014.

[12] Ashish Tewari. Atmospheric and Space Flight Dynamics, Modeling and Simulation with Matlab and Simulink.

[13] Prasun N. Desai Jill L. Prince and Myron. R. Grover Eric M. Queen. "mars phoenix entry, descent, and landing simulation design and modelling analysis". Journal of Spacecrafts and Rockets, Vol. 48 No. 5, 2011.

[14] LIU Lin ZHOU Chui-hong, YU Sheng-xian. "analytical solution of coupled perturbation of tesseral harmonic terms of mars non-spherical gravitational potential". Chinese Astronomy and Astrophysics 36, 2012.

[15] S.R. Lewis F. Forget, E. Millour. "mars climate database v5.1". ESA, 2015.

[16] David J. Kinney. "aerothermal anchoring of cbaero using high fidelity cfd". Conference Paper. NASA Ames Research Center, 2007.

[17] Robert D. Braun Scott K. Martinelli. "centerline heating methodology for use in preliminary design studies". American Institute of Aeronautics and Astronautics, 2010 .

[18] NASA Mars Architecture Steering Group Bret G. Drake. "human exploration of mars design reference architecture 5.0.". Report. National Aeronautics and Space Administration, 2009.

[19] Lynn Craig McGrew Gavin F. Mendeck. "entry guidance design and postflight performance for 2011 mars science laboratory mission". Journal of Spacecraft and Rockets, Vol. 51, No. 4, 2014.

[20] Ron Sostaric. "the challenge of mars edl (entry, descent, and landing)". NASA Johnson Space Center, 2010.

[21] Evgeniy Sklyanskiy Robert Braun Humphrey Price, Robert Manning. "a highheritage blunt-body entry, descent, and landing concept for human mars exploration". 54th AIAA Aerospace Sciences Meeting, 2016. 
22] Ashley M. Korzun Ian G. Clark Michael J. Grant Bradley A. Steinfeldt John E. Theisinger and Robert D. Braun. "high mass mars entry, descent, and landing architecture assessment". Conference Paper. AIAA, 2009.

[23] National Aeronautics and Space Administration. "space launch system". NASA facts. George C. Marshall Space Flight Center, 2012.

[24] Armin Herbertz Josef Klevanski Holger Burkhardt, Martin Sippel. "comparative study of kerosene and methane propellant engines for reusable liquid booster stages". 4th International Conference on Launcher Technology "Space Launcher Liquid Propulsion, 2002.

[25] Dr. Anthony M. Calomino Henry S. Wright Mary Elizabeth Wusk Monica F. Hughes Stephen J. Hughes, Dr. F. McNeil Cheatwood. "hypersonic inflatable aerodynamic decelerator (hiad) technology development overview". NASA, 2013.

[26] Ian Fernandez Kenneth R. Hamm Jr. David Kinney Bernard Laub Alberto Makino Mary Kathleen McGuire Keith Peterson Dinesh Prabhu Daniel Empey Ian Dupzyk Loc Huynh Prabhat Hajela Peter Gage Austin Howard Ethiraj Venkatapathy, James Arnold. "adaptive deployable entry and placement technology (adept): A feasibility study for human missions to mars". AIAA, 2011.

[27] Dinesh K. Prabhu Brian R. Hollis. " assessment of laminar, convective aeroheating prediction uncertainties for mars entry vehicles". Conference Paper. American Institute of Aeronautics and Astronautics, 2011.

[28] Michael J. Wrightz Karl T. Edquist Artem A. Dyakonovy and Chun Y. Tang. "aerothermodynamic design of the mars science laboratory heatshield". AIAA Thermophysics Conference, 2009. 